\title{
Neck Pain Following Cervical Laminoplasty: Does Preservation of the C2 Muscle Attachments and/or C7 Matter?
}

\author{
K. Daniel Riew ${ }^{1}$ Annie L. Raich ${ }^{3}$ Joseph R. Dettori ${ }^{3}$ John G. Heller ${ }^{2}$
}

${ }^{1}$ Department of Orthopedic Surgery, Washington University, St. Louis,

Address for correspondence K. Daniel Riew, MD, Department of Orthopedic Surgery, Washington University, 660 South Euclid Avenue, Missouri, United States

2 Department of Orthopaedic Surgery, Emory Spine Center, Atlanta, Campus Box 8233, St. Louis, MO 63110, United States Georgia, United States

${ }^{3}$ Spectrum Research, Inc., Tacoma, Washington, United States (e-mail: riewd@wudosis.wustl.edu).

Evid Based Spine Care J 2013:4:42-53.

\begin{abstract}
Keywords

- laminoplasty

- axial neck pain

- C7 preservation

- semispinalis cervicis

- C3 laminectomy

Study Design Systematic review.

Objective In patients aged 18 years or older, with cervical spondylotic myelopathy or ossification of the posterior longitudinal ligament (OPLL), does sparing the C2 muscle attachments and/or C7-preserving cervical laminoplasty lead to reduced postoperative axial pain compared with conventional C3 to C7 laminoplasty? Do these results vary based on early active postoperative cervical motion?

Methods A systematic review of the English-language literature was undertaken for articles published between 1970 and August 17, 2012. Electronic databases and reference lists of key articles were searched to identify studies evaluating C2/C3- or C7-preserving cervical laminoplasty for the treatment of cervical spondylotic myelopathy (CSM) or OPLL in adults. Studies involving traumatic onset, cervical fracture, infection, deformity, or neoplasms were excluded, as were noncomparative studies. Two independent reviewers assessed the level of evidence quality using the grading of recommendations assessment, development and evaluation (GRADE) system, and disagreements were resolved by consensus.

Results We identified 11 articles meeting our inclusion criteria. Only the randomized controlled trial (RCT) showed no significant difference in late axial pain (at 12 months) when C7 spinous muscle preservation was compared with no preservation. However, seven other retrospective cohort studies showed significant pain relief in the preserved group compared with the nonpreserved group. The preservation group included those with preservation of the $\mathrm{C} 7$ spinous process and/or attached muscles, the deep extensor muscles, or C2 muscle attachment and/or C3 laminectomy (as opposed to laminoplasty). One study that included preservation of either the $\mathrm{C} 2$ or $\mathrm{C} 7$ posterior paraspinal muscles found that only preservation of the muscles attached to $C 2$ resulted in reduced postoperative pain. Another study that included preservation of either the $\mathrm{C} 7$ spinous process or the deep extensor muscles found that only preservation of $\mathrm{C} 7$ resulted in reduced postoperative pain.
\end{abstract}

received

October 29, 2012

accepted

December 5, 2012 (c) 2013 Georg Thieme Verlag KG Stuttgart · New York
DOI http://dx.doi.org/ 10.1055/s-0033-1341606. ISSN 1663-7976. 
Conclusion Although there is conflicting data regarding the importance of preserving or the semispinalis cervicis muscle attachments to $\mathrm{C} 2$, there is enough/or the semispinalis cervicis muscle attachments to $C 2$, there is enough evidence to suggest that surgeons should make every attempt to preserve these structures whenever possible since there appears to be little downside to doing so, unless it compromises the neurologic decompression.

\section{Study Rationale and Context}

The most important extensor muscle of the cervical spine is the semispinalis cervicis muscle, which originates from the transverse processes of the upper thoracic vertebrae and inserts into the spinous processes of $\mathrm{C} 2$ through $\mathrm{C} 5$, with the most important insertion being at $\mathrm{C} 2$. Disruption of this insertion can result in kyphosis, and possibly axial neck pain. Another important structure for neck extension is the spinous process of $\mathrm{C} 7$, the vertebra prominens. The height of this spinous process increases the moment arm of the extensor muscle complex. Theoretically, at least, loss of the $\mathrm{C} 7$ spinous process height or muscular insertion into $\mathrm{C} 2$ might result in cervical kyphosis and axial neck pain. The purpose of this article is to perform a systematic review of the available relevant literature to determine the effect on axial neck pain of preserving the $\mathrm{C} 7$ spinous process and the semispinalis cervicis insertion into $\mathrm{C} 2$.

\section{Objective or Clinical Question}

In patients 18 years or older, with cervical spondylotic myelopathy (CSM) or ossification of the posterior longitudinal ligament (OPLL), does a C2 muscle attachment and/or C7-preserving cervical laminoplasty lead to reduced postoperative axial pain compared with conventional C3 through C7 laminoplasty? Are these results altered by early active postoperative cervical motion?

\section{Methods}

Study Design: Systematic review.

Search: PubMed, Cochrane, and National Guideline Clearinghouse Databases; bibliographies of key articles.

Dates Searched: Up through August 17, 2012.

Inclusion Criteria: Studies directly comparing $\mathrm{C} 2 / \mathrm{C} 3$ or $\mathrm{C} 7$ preserving with conventional nonpreserving cervical laminoplasty in patients 18 years or older with CSM or OPLL.

Exclusion Criteria: Studies in patients younger than 18 years, those with a cervical fracture, neoplasm, infection, or deformity; noncomparative studies, comparative studies with fewer than 10 patients per treatment group; nonhuman in vivo, in vitro, and biomechanical studies.

Outcomes: Pain (visual analog scale [VAS], Hosono criteria). Analysis: Descriptive statistics, means, standard deviation, and ranges were abstracted from the original reports as available. Mean percentage improvement in VAS scores was calculated by dividing the change score from baseline to follow-up by the baseline score. Pooling of data was not done due to concerns regarding study quality and heterogeneity of treatments and study populations. We attempted to answer the question of the effect of early motion on pain by stratifying the results based on the length of collar use.

Overall Strength of Evidence: Risk of bias for individual studies was based on using criteria set by The Journal of Bone and Joint Surgery ${ }^{1}$ modified to delineate criteria associated with methodological quality and risk of bias based on recommendation from the Agency for Healthcare Research and Quality. ${ }^{2,3}$ The overall strength of evidence across studies was based on precepts outlined by the Grading of Recommendations Assessment, Development and Evaluation (GRADE) Working Group ${ }^{4}$ and recommendations made by the Agency for Healthcare Research and Quality (AHRQ). ${ }^{2,3}$ (See online supplementary material.)

\section{Results}

From a total of 135 citations retrieved, 13 were evaluated for full-text review, and 11 met the inclusion criteria for this report (-Fig. 1). Five studies evaluated cervical laminoplasty using the open-door technique and six studies used the French-door technique. The included studies examined preservation compared with nonpreservation of C2/C3 (two studies) or C7 (six studies) spinous process and attached muscles or ligaments, the deep extensor muscles at C2 and/or C7 (four studies), or the nuchal ligament at C6 to C7 (one study); two studies compared

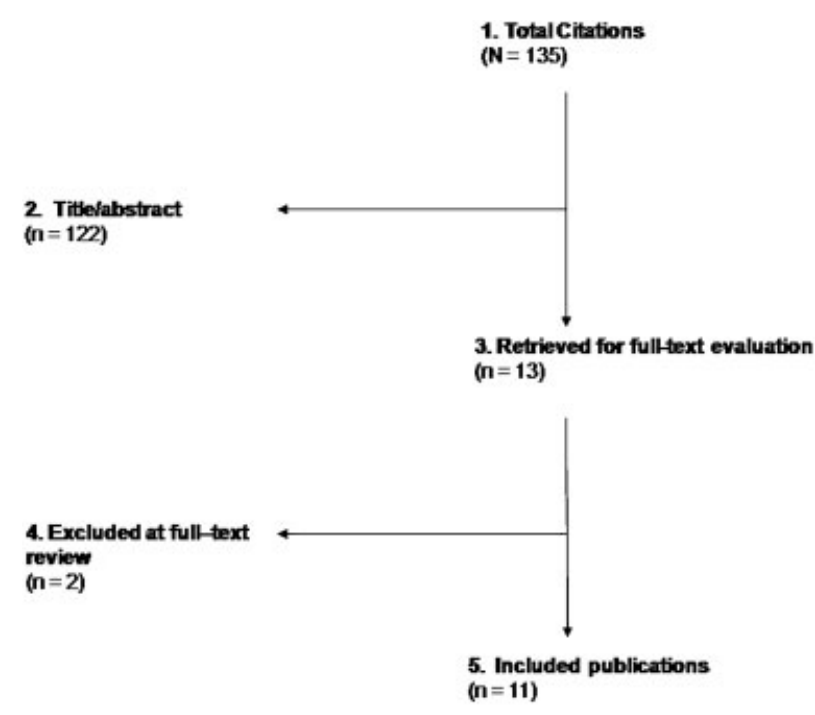

Fig. 1 Flow chart showing results of literature search. 
three treatment groups (-Table $\mathbf{1}$ ). The study populations comprised CSM patients only or a mixture of mostly CSM and OPLL patients. Populations in included studies were predominantly male and middle aged. With the exception of one randomized controlled trial (RCT) (CoE II), all studies are retrospective cohort studies (CoE III).

\section{Preservation of C2 Muscle Attachment with a C3 Laminectomy versus Nonpreservation}

Pain Measured as Decreased, Complete Relief, or Any Two retrospective cohort studies reported less axial pain with preservation of the $\mathrm{C} 2$ muscle attachment compared with no preservation at 24 months $^{5}$ or 17 to 30 months. ${ }^{6}$ This was done by performing a laminectomy of $\mathrm{C} 3$, instead of a laminoplasty, since a laminoplasty requires more muscle detachment at $\mathrm{C} 2$ and also adds bulk to the area where the muscle attaches.

- Kato et al reported a significantly decreased proportion of patients in the preserved group experiencing postoperative pain in a multivariate analysis (odds ratio $=0.13,95 \%$ confidence interval: 0.02 to 0.98$).^{5}$

- Takeuchi et al reported that significantly more patients in the preserved group (52.5\% with no pain, $47.5 \%$ with any pain) experienced complete relief of symptoms compared with the nonpreserved group (19\% with no pain, $81 \%$ with any pain, $p=0.035$ ). The proportion of patients whose pain was made worse by the surgery was significantly smaller in the preserved group (17.5\% worsened) compared with the nonpreserved group (50\% worsened, $p=0.02$ ). ${ }^{6}$

\section{Preservation of C7 versus Nonpreservation}

\section{Pain Measured as Severity or Any}

Two studies reported no difference in axial pain with $\mathrm{C7}$ preservation compared with nonpreservation at 24 months ${ }^{5}$ or 12 months. $^{7}$

- An RCT showed no significant difference in severity or incidence of any late axial pain when C7 spinous muscle preservation was compared with no preservation. ${ }^{7}$

- Kato et al reported that preservation of the muscles attached to $\mathrm{C} 7$ resulted in a similar proportion of patients experiencing postoperative axial pain compared with nonpreservation in multivariate analysis (odds ratio $=0.7,95 \%$ confidence interval: 0.16 to 0.13$)^{5}$

\section{Pain Measured per Hosono Criteria (- Table 2)}

- Three studies reported early axial pain ranging from 15 to $56 \%$ in the C7-preserved group compared with 49 to $86 \%$ in the nonpreserved group. ${ }^{8-10}$ The preserved group experienced significantly less pain than the nonpreserved group in two of the studies. ${ }^{9,10}$

- Four studies reported late axial pain ranging from 5.4 to $38 \%$ in the preserved group compared with 30 to $73 \%$ in the nonpreserved group. ${ }^{7-10}$ The preserved group experienced significantly less pain than the nonpreserved group in two of the studies. ${ }^{9,10}$
Pain Measured by VAS (-Table 3; - Fig. 2)

Two studies were inconsistent in their results of axial pain.

- In Takeuchi et al, the C7-preserved group had significantly improved VAS scores at 12 and 24 months compared with the nonpreserved group, while Kowatari et al reported that no significant difference was seen between the C7preserved group and the nonpreserved group in VAS pain score at 12 months. ${ }^{7,11}$

Aggravation of Symptoms (see online supplementary material)

- One study found that aggravation of symptoms at a late postoperative period was significantly less common in the C7-preserved group (12\%) compared with the nonpreserved group $(66 \%, p=0.002){ }^{8}$

\section{Other Types of Preservation}

Pain Measured per Hosono Criteria (-Table 2)

- Three studies using different preservation techniques reported early axial pain ranging from 15 to $21 \%$ in the deep extensor muscle or nuchal ligament preserved group compared with 17 to $49 \%$ in the nonpreserved group. ${ }^{10,12,13}$ The C7 deep extensor muscle-preserving group experienced significantly less pain than the nonpreserved group in one of the studies. ${ }^{10}$

- These three studies also reported late axial pain ranging from 5 to $11 \%$ in the preserved group compared with 6 to $30 \%$ in the nonpreserved group. ${ }^{10,12,13}$ The group preserving the deep extensor muscles at $\mathrm{C} 7$ experienced significantly less pain than the nonpreserved group in one of the studies. ${ }^{10}$

\section{Pain Measured by VAS (-Table 3; - Fig. 2)}

- Two studies using deep extensor muscle preservation reported on VAS pain at 6 or 38 months. ${ }^{14,15}$ In one study, the muscle-preserved group experienced significantly less pain at 38 months $(2.3 \pm 2.3)$ compared with the nonpreserved group $(4.9 \pm 2.6, p=0.05) .^{14}$

- In the other study, the muscle-preserved group experienced significantly greater mean percentage improvement in VAS pain score at 6 months compared with the nonpreserved group. $^{15}$

\section{Effect of Early Motion (-Figs. 3 and 4)}

None of the included studies conducted a formal analysis of the effect of early cervical motion on postoperative axial pain.

- Seven studies reported the use of a collar ranging from 1 to 8 weeks, ${ }^{5-9,12,13}$ two studies reported that no collar was used, ${ }^{14,15}$ and two studies did not report on collar use. ${ }^{10,11}$

- The effect of early motion on early and late axial pain is shown in -Figs. 3 and $\mathbf{4}$. There appears to be a trend of increasing postoperative axial pain with increasing length of collar use; however, these studies comprise different types of laminoplasty procedures, preservation techniques, follow-up time, and collar type and length of use. No data were available to compare collar use to no collar use. 


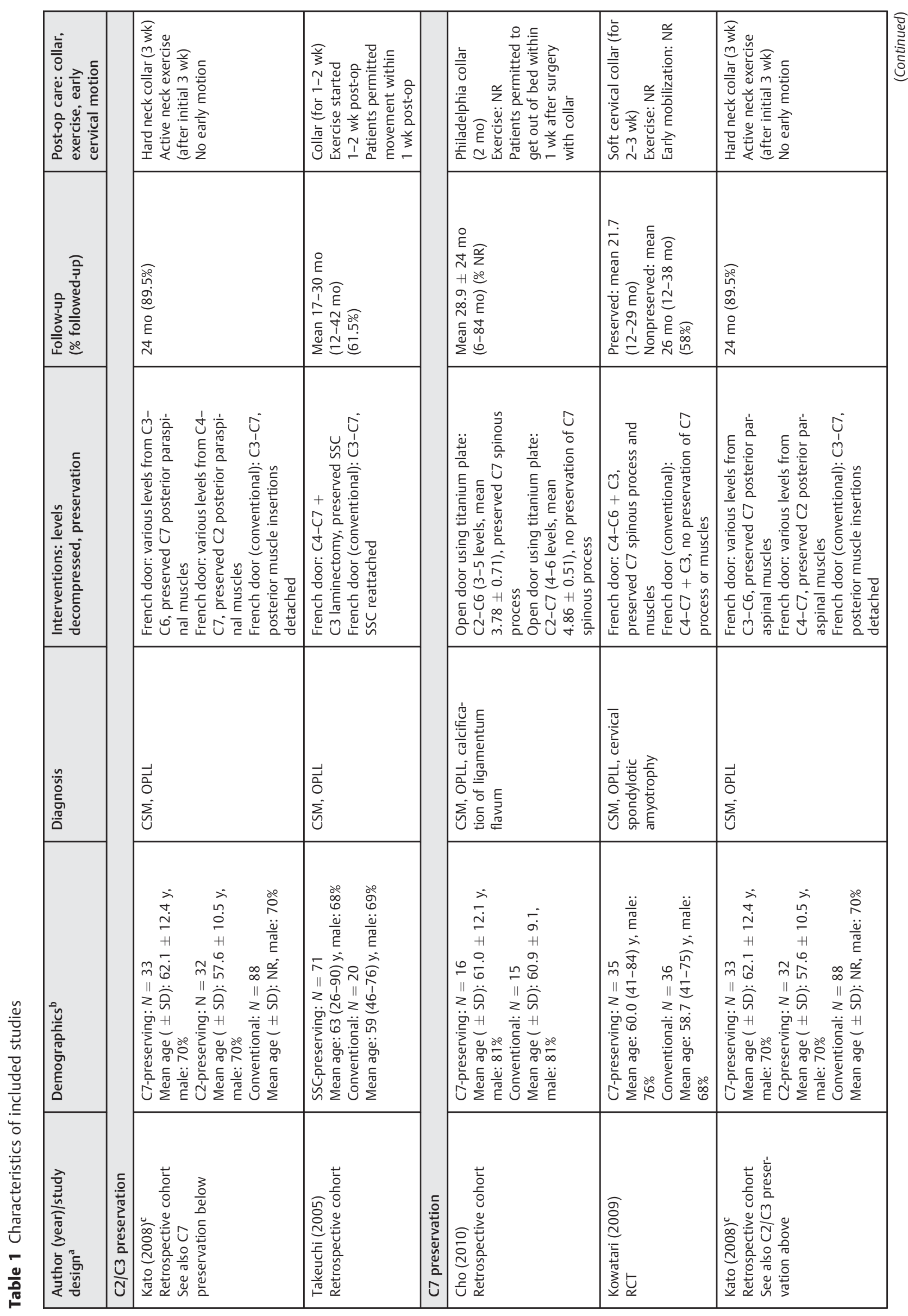




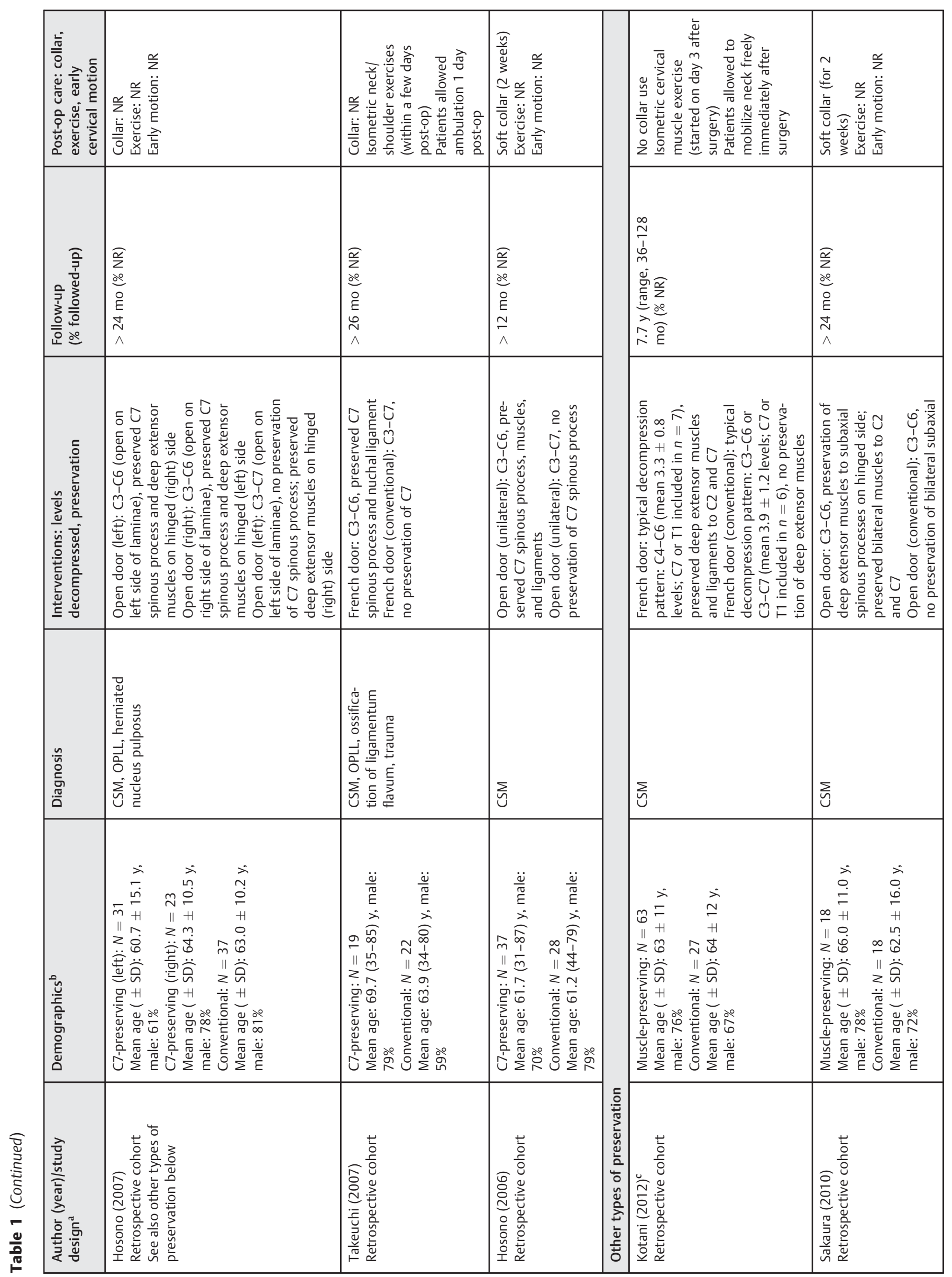



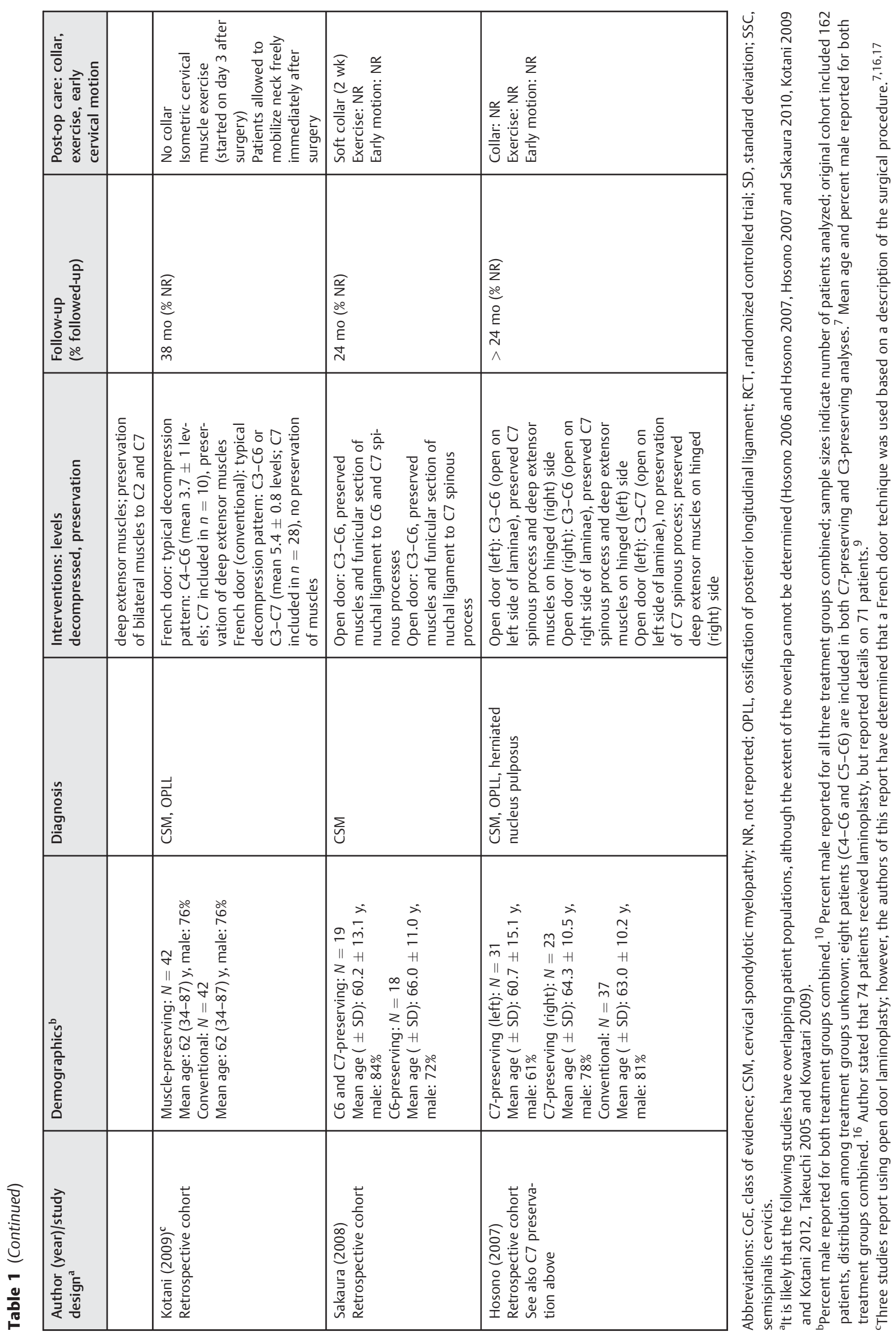
Table 2 Early and late axial pain according to Hosono criteria ${ }^{a}$

\begin{tabular}{|c|c|c|c|c|}
\hline $\begin{array}{l}\text { Study (year) } \\
\text { Type of laminoplasty }\end{array}$ & $\begin{array}{l}\text { Category(ies) of } \\
\text { preservation }\end{array}$ & $\begin{array}{l}\text { Preserved } \\
\text { group } \\
\text { (\% of patients) }\end{array}$ & $\begin{array}{l}\text { Nonpreserved } \\
\text { group } \\
\text { (\% of patients) }\end{array}$ & $p$-Value \\
\hline \multicolumn{5}{|l|}{ Pre-op axial pain } \\
\hline $\begin{array}{l}\text { Cho }(2010) \\
\text { Open door }\end{array}$ & C7 (spinous process) & 19 & 20 & NR \\
\hline \multicolumn{5}{|l|}{ Early axial pain ${ }^{b}$} \\
\hline $\begin{array}{l}\text { Cho }(2010) \\
\text { Open door }\end{array}$ & C7 (spinous process) & 56 & 86 & NR \\
\hline $\begin{array}{l}\text { Hosono }(2006) \\
\text { Open door }\end{array}$ & C7 (spinous process) & 16 & 50 & 0.006 \\
\hline $\begin{array}{l}\text { Hosono }(2007)^{c} \\
\text { Open door }\end{array}$ & $\begin{array}{l}\text { C7 (spinous process) and other } \\
\text { preservation (deep extensor } \\
\text { muscles at C7) }\end{array}$ & 15 & 49 & 0.0008 \\
\hline $\begin{array}{l}\text { Sakaura (2010) } \\
\text { Open door }\end{array}$ & $\begin{array}{l}\text { Other preservation (deep exten- } \\
\text { sor muscles at } C 2 \text { and } C 7 \text { on } \\
\text { hinged side) }\end{array}$ & 16.7 & 22.2 & NS \\
\hline $\begin{array}{l}\text { Sakaura (2008) } \\
\text { Open door }\end{array}$ & $\begin{array}{l}\text { Other preservation (funicular } \\
\text { section of nuchal ligament to C6 } \\
\text { and }(7)\end{array}$ & 21 & 17 & NS \\
\hline \multicolumn{5}{|l|}{ Late axial pain ${ }^{\mathrm{b}}$} \\
\hline $\begin{array}{l}\text { Cho }(2010) \\
\text { Open door }\end{array}$ & C7 (spinous process) & 12 & 73 & NR \\
\hline $\begin{array}{l}\text { Hosono }(2006) \\
\text { Open door }\end{array}$ & C7 (spinous process) & 5.4 & 29 & 0.015 \\
\hline $\begin{array}{l}\text { Hosono }(2007)^{\mathbf{b}} \\
\text { Open door }\end{array}$ & $\begin{array}{l}\text { C7 (spinous process) and other } \\
\text { preservation (deep extensor } \\
\text { muscles at C7) }\end{array}$ & 6 & 30 & 0.0036 \\
\hline $\begin{array}{l}\text { Kowatari }(2009)^{\mathbf{d}} \\
\text { French door }\end{array}$ & $\begin{array}{l}\text { C7 (spinous process and attached } \\
\text { muscles) }\end{array}$ & 38 & 37 & NR \\
\hline $\begin{array}{l}\text { Sakaura (2010) } \\
\text { Open door }\end{array}$ & $\begin{array}{l}\text { Other preservation (deep exten- } \\
\text { sor muscles at } C 2 \text { and } C 7 \text { on } \\
\text { hinged side) }\end{array}$ & 11.1 & 11.1 & NS \\
\hline $\begin{array}{l}\text { Sakaura (2008) } \\
\text { Open door }\end{array}$ & $\begin{array}{l}\text { Other preservation (funicular } \\
\text { section of nuchal ligament to C6 } \\
\text { and }(7)\end{array}$ & 5 & 6 & NS \\
\hline
\end{tabular}

Abbreviations: NR, not reported; NS, not significant.

Note: Axial pain/symptoms is defined as neck pain with neck stiffness, shoulder stiffness, or both ${ }^{8}$; neck and/or shoulder girdle pain that worsened after a long period of sitting or standing ${ }^{1}$; or not defined. ${ }^{9,10,16,17}$

${ }^{a}$ Hosono pain grading: severe (analgesics or injection of anesthetics to the painful muscles regularly needed), moderate (physical therapy including massage or thermotherapy for the painful muscles regularly needed), mild (no treatment needed). ${ }^{9}$

${ }^{b}$ Early axial pain is defined as severe or moderate axial pain persisting for more than 1 wk during the first month after surgery. Late axial pain is defined as severe or moderate axial pain persisting for more than 1 mo after surgery. ${ }^{9}$ Summation of moderate and severe percentages from original data for pre-op, early, and late axial pain. ${ }^{8}$

${ }^{\mathrm{C}}$ Results for preserved group combine the open left and open right treatment groups. ${ }^{10}$

${ }^{\mathrm{d}}$ Late axial pain is defined as severe or moderate pain measured at 1 year $\mathrm{F} / \mathrm{U}$, duration of pain NR. ${ }^{1}$

\section{Clinical Guidelines}

Guidelines were found addressing cervical laminoplasty for the treatment of CSM; however, these guidelines did not recommend any particular laminoplasty approach. ${ }^{16,17}$

\section{Evidence Summary (-Table 4)}

The overall strength of evidence evaluating $\mathrm{C} 2 / \mathrm{C} 3$ or $\mathrm{C} 7-$ preserving laminoplasty compared with nonpreserving lam- inoplasty with respect to patient-reported pain outcomes is low, meaning we have low confidence that the evidence reflects the true effect and that further research is likely to change the confidence in the estimate of effect and likely to change the estimate.

\section{Illustrative Case}

The patient is a 52-year-old male with cervical myelopathy due to OPLL. He had mild axial neck pain preoperatively, but 
Table 3 Mean visual analog scale (VAS) pain scores from preoperative to follow-up

\begin{tabular}{|c|c|c|c|c|}
\hline \multirow[t]{2}{*}{$\begin{array}{l}\text { Study (year) } \\
\text { Type of laminoplasty }\end{array}$} & \multirow[t]{2}{*}{ Category(ies) of preservation } & \multicolumn{3}{|c|}{$\begin{array}{l}\text { VAS mean } \pm \text { SD or (range) } \\
\left(\% \text { improvement from pre-op) }{ }^{a}\right.\end{array}$} \\
\hline & & $\begin{array}{l}\text { Preserved } \\
\text { group }\end{array}$ & $\begin{array}{l}\text { Nonpreserved } \\
\text { group }\end{array}$ & $\begin{array}{l}p \text {-Value } \\
\text { (preserved vs. } \\
\text { nonpreserved } \\
\text { mean score) }\end{array}$ \\
\hline \multicolumn{5}{|l|}{ Pre-op } \\
\hline $\begin{array}{l}\text { Kotani (2012) } \\
\text { French door }\end{array}$ & $\begin{array}{l}\text { Other preservation (deep } \\
\text { extensor muscles at C2 and C7) }\end{array}$ & $4.1 \pm 3.3$ & $5.5 \pm 4.0$ & NS \\
\hline $\begin{array}{l}\text { Kotani (2009) } \\
\text { French door }\end{array}$ & $\begin{array}{l}\text { Other preservation (deep } \\
\text { extensor muscles at C2 and/or } \\
\text { C7) }\end{array}$ & $3.5 \pm 3.2^{b}$ & $3.5 \pm 3.2^{b}$ & NA \\
\hline $\begin{array}{l}\text { Takeuchi (2007) } \\
\text { French door }\end{array}$ & $\begin{array}{l}\text { C7 (spinous process and nuchal } \\
\text { ligament) }\end{array}$ & $5.4 \pm 1.7$ & $5.6 \pm 1.4$ & 0.506 \\
\hline \multicolumn{5}{|l|}{$6 \mathrm{mo}$} \\
\hline $\begin{array}{l}\text { Kotani (2012) } \\
\text { French door }\end{array}$ & $\begin{array}{l}\text { Other preservation (deep } \\
\text { extensor muscles at C2 and C7) }\end{array}$ & $2.8 \pm 2.5(31.7 \%)$ & $4.5 \pm 2.4(18.2 \%)$ & $<0.01$ \\
\hline \multicolumn{5}{|l|}{$12 \mathrm{mo}$} \\
\hline $\begin{array}{l}\text { Kowatari (2009) } \\
\text { French door }\end{array}$ & $\begin{array}{l}\text { C7 (spinous process and attached } \\
\text { muscles) }\end{array}$ & 2.9 & 3.5 & NS \\
\hline $\begin{array}{l}\text { Takeuchi (2007) } \\
\text { French door }\end{array}$ & $\begin{array}{l}\text { C7 (spinous process and nuchal } \\
\text { ligament) }\end{array}$ & $2.4 \pm 1.9(55.6 \%)$ & $6.4 \pm 1.7(-14.3 \%)$ & $<0.05$ \\
\hline \multicolumn{5}{|l|}{24 mo } \\
\hline $\begin{array}{l}\text { Takeuchi (2007) } \\
\text { French door }\end{array}$ & $\begin{array}{l}\text { C7 (spinous process and nuchal } \\
\text { ligament) }\end{array}$ & $2.3 \pm 1.8(57.4 \%)$ & $6.2 \pm 1.9(-10.7 \%)$ & $<0.05$ \\
\hline \multicolumn{5}{|l|}{$38 \mathrm{mo}$} \\
\hline $\begin{array}{l}\text { Kotani (2009) } \\
\text { French door }\end{array}$ & $\begin{array}{l}\text { Other preservation (deep } \\
\text { extensor muscles at C2 and/or } \\
\text { C7) }\end{array}$ & $2.3 \pm 2.3$ & $4.9 \pm 2.6$ & 0.05 \\
\hline \multicolumn{5}{|l|}{$7.7 \mathrm{y}$} \\
\hline $\begin{array}{l}\text { Kotani (2012) } \\
\text { French door }\end{array}$ & $\begin{array}{l}\text { Other preservation (deep exten- } \\
\text { sor muscles at C2 and C7) }\end{array}$ & $2.2 \pm 2.2(46.3 \%)$ & $4.3 \pm 2.4(21.8 \%)$ & $<0.01$ \\
\hline
\end{tabular}

Abbreviations: NA, not applicable; NS, not significant; SD, standard deviation; VAS, visual analog scale.

aAS reported on $0-10 \mathrm{~mm}$ scale ${ }^{11,12,15}$; reported on a $0-100 \mathrm{~mm}$ scale and normalized to a $0-10 \mathrm{~mm}$ scale for comparison purposes. ${ }^{1}$

${ }^{b}$ Mean VAS reported for combined treatment groups at pre-op, no significant difference in VAS score between the groups. ${ }^{11}$

said that he could live with the pain as long as the myelopathy is resolved. When given a choice between fusion with laminectomy, which would limit his motion, and a laminoplasty, he chose the latter. A C3 laminectomy and C4 to C6 laminoplasty were performed. He had no worsening of his axial neck pain and felt that it was often better than it was preoperatively. - Fig. 5 shows the preoperative lateral radiograph. -Fig. 6a, b shows the sagittal CT views. - Fig. $\mathbf{7}$ is the postoperative lateral radiograph, showing the C3 laminectomy and laminoplasty of C4 to C6 with plates.

\section{Discussion}

- This systematic review is limited by the following:

- Axial pain/symptoms were variously defined or not defined at all.

- There was no indication in the literature of the reliability, validity, or responsiveness of the Hosono pain grading criteria in this or any other patient population. - Loss to follow-up was not reported in the majority of studies.

- All but one of the studies was CoE III. 


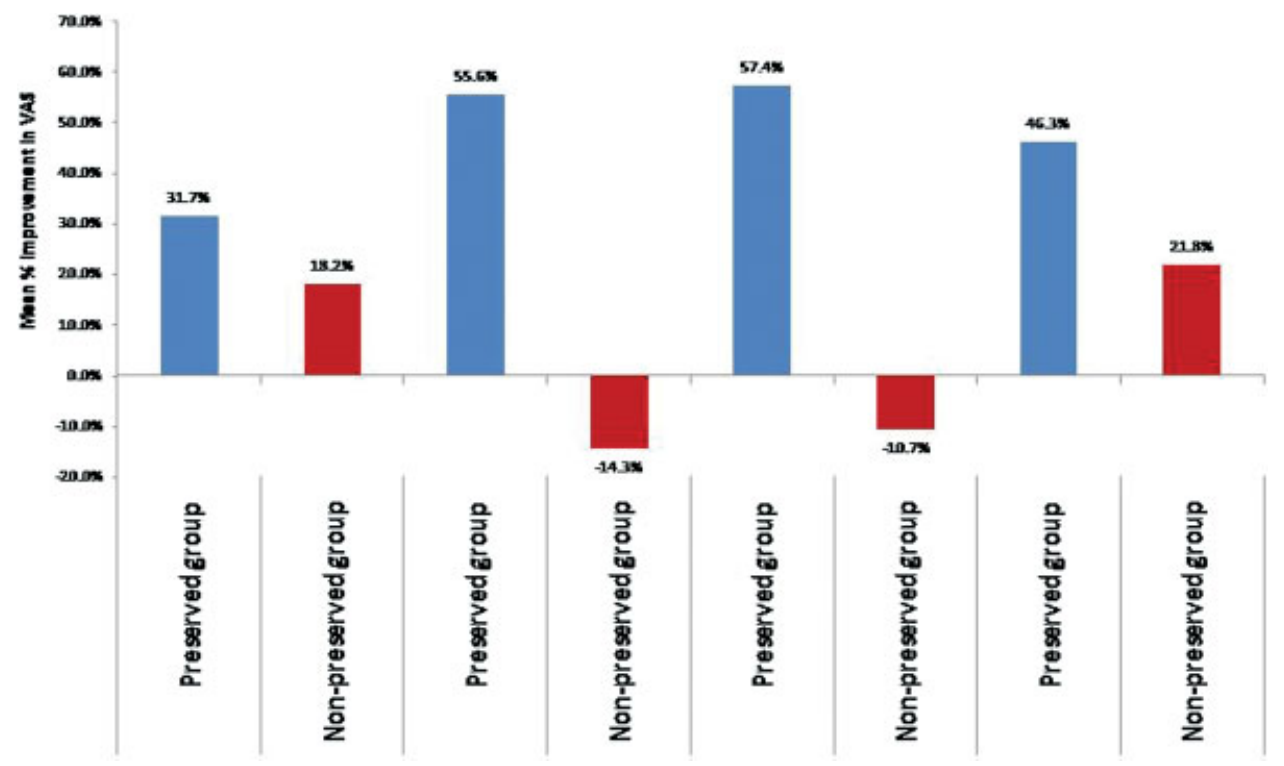

Fig. 2 Overall mean percent improvement in visual analog scale (VAS) pain score at last follow-up for two studies.

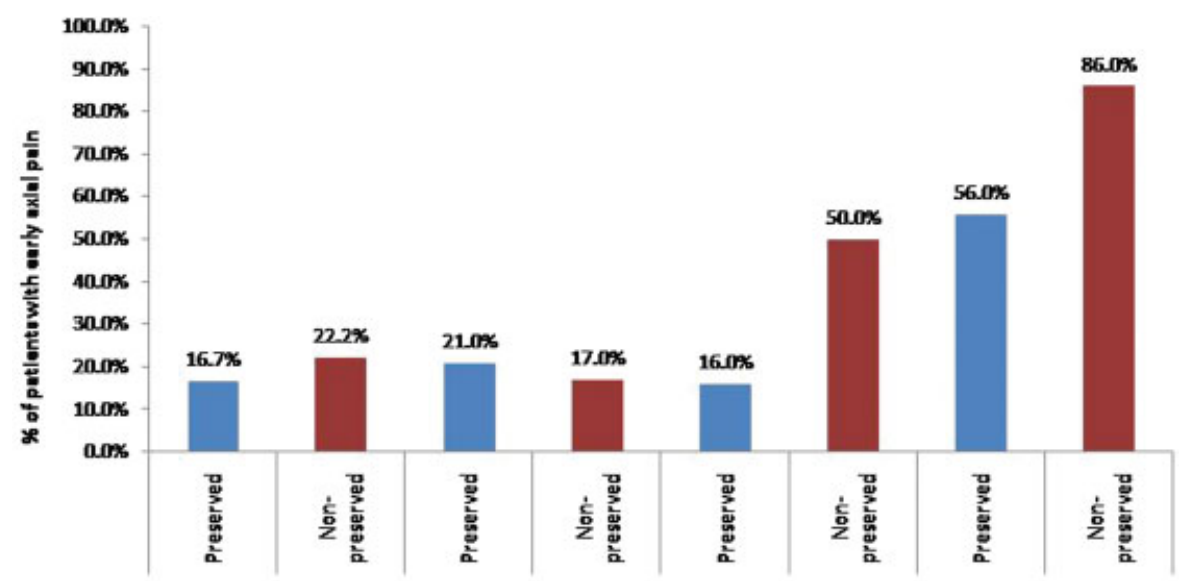

Fig. 3 Collar use and early axial pain for studies grading pain using the Hosono criteria.

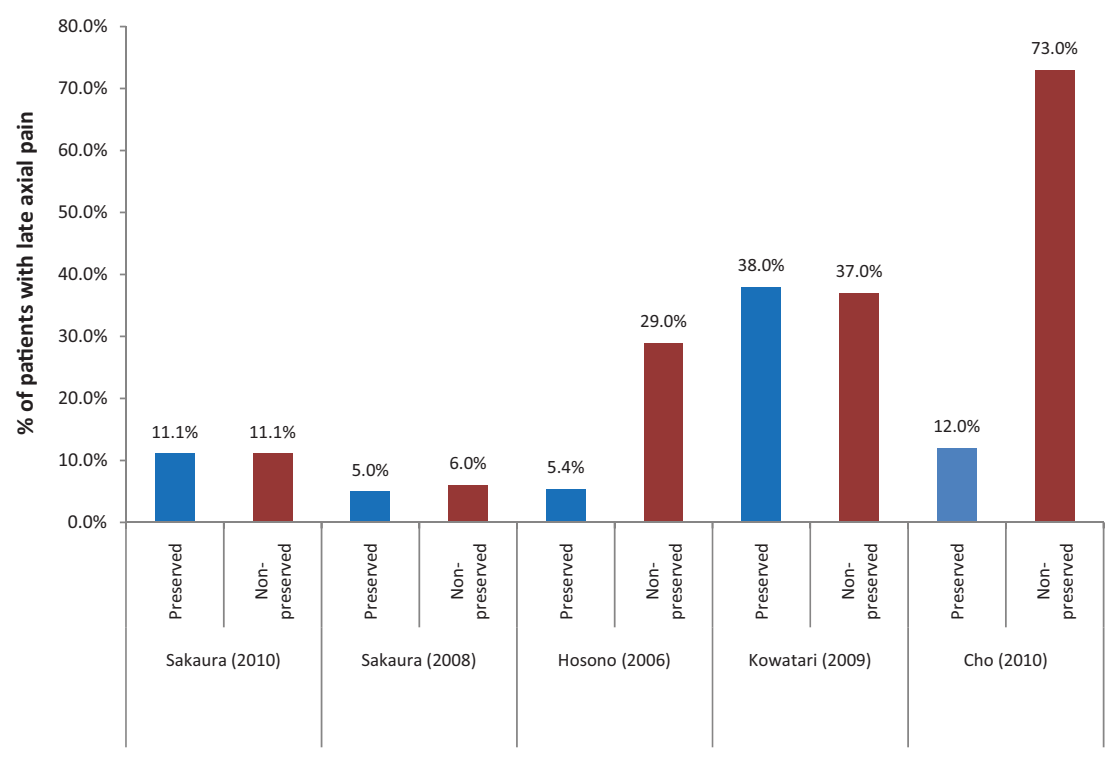

Fig. 4 Collar use and late axial pain for studies grading pain using the Hosono criteria. 
Table 4 Summary of strength of evidence

\begin{tabular}{|c|c|c|c|c|c|}
\hline & $\begin{array}{l}\text { Strength of } \\
\text { evidence }\end{array}$ & Conclusions/comments & Baseline & Upgrade (levels) & $\begin{array}{l}\text { Downgrade } \\
\text { (levels) }\end{array}$ \\
\hline \multicolumn{6}{|c|}{ Patient-reported outcomes } \\
\hline $\begin{array}{l}\text { Improvement } \\
\text { in pain (VAS or } \\
\text { Hosono criteria) }\end{array}$ & Low & $\begin{array}{l}\text { - The only RCT included in this report } \\
\text { found no significant difference in } \\
\text { axial pain between C7-preserved } \\
\text { and nonpreserved groups. } \\
\text { - Both C2-preservation studies and } \\
\text { two-thirds of the C7-preservation } \\
\text { studies showed improved pain } \\
\text { relief in the C2 or C7 preservation } \\
\text { group. One of these cohort studies } \\
\text { comparing C2 and C7 preservation } \\
\text { to nonpreservation found that C2 } \\
\text { preservation resulted in reduced } \\
\text { pain compared with nonpreserva- } \\
\text { tion, but C7 preservation and } \\
\text { nonpreservation had similar pain } \\
\text { outcomes. } \\
\text { - None of the included studies } \\
\text { conducted a formal analysis of the } \\
\text { effect of early cervical motion on } \\
\text { postoperative pain. }\end{array}$ & Low & & \\
\hline
\end{tabular}

Abbreviations: RCT, randomized controlled trial; VAS, visual analog scale.

Baseline quality: High = majority of articles Level I/II. Low = majority of articles Level III/IV.

Upgrade: Large magnitude of effect (1 or 2 levels); dose response gradient (1 level).

Downgrade: Inconsistency of results (1 or 2 levels); indirectness of evidence ( 1 or 2 levels); imprecision of effect estimates ( 1 or 2 levels).

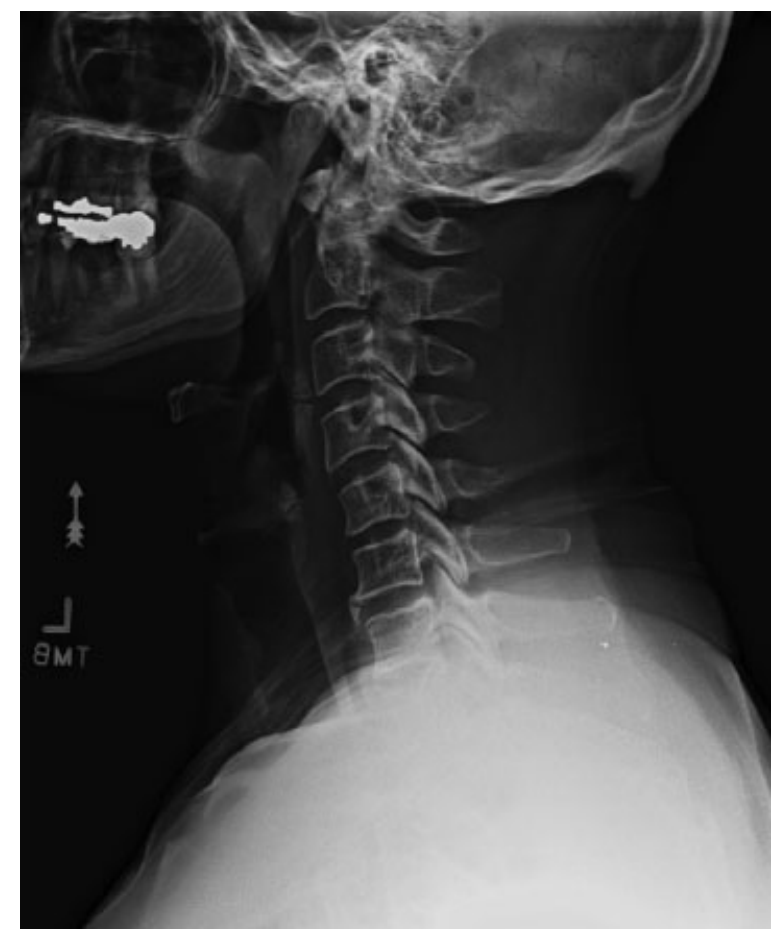

Fig. 5 Preoperative lateral.
- Five of the studies had a relatively small sample size $(<$ 70 patients).

- Several studies' treatment groups comprised different time periods, resulting in potential differences between the groups regarding surgical technique or postoperative care.

- Despite the low strength of evidence, we conclude that:

- There is no downside to using techniques to preserve $\mathrm{C} 7$ or the semispinalis cervicis attachment to $\mathrm{C} 2$, as long as the neurologic decompression is not compromised.

- Whenever possible, surgeons should attempt to preserve the attachments of the semispinalis cervicis to C2. C3 laminectomy, instead of laminoplasty, helps to achieve this.

- If an adequate decompression can be achieved without including C7 in the laminoplasty, it should be preserved with its muscle attachments.

\section{Funding}

Analytic support for this work was provided by Spectrum Research, Inc. with funding from AOSpine.

\section{Conflict of Interest}

John G. Heller received royalties from Medtronic for a device related to this topic, and also owns stock shares and has consulted for Medtronic. 

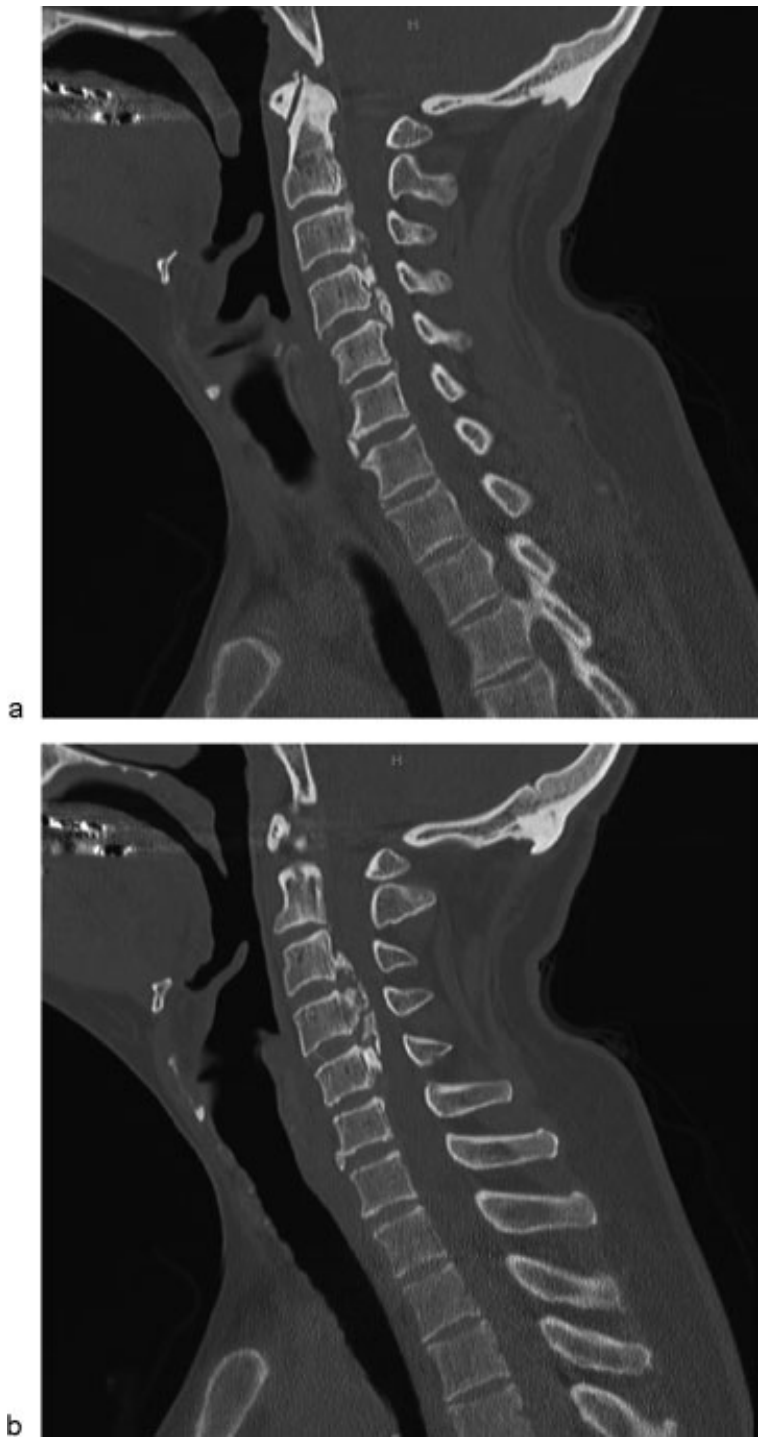

Fig. 6 (a) Parasagittal preoperative CT image demonstrating severe ossification of the posterior longitudinal ligament (OPLL). (b) Midsagittal preoperative CT image demonstrating severe OPLL.

\section{References}

1 Wright JG, Swiontkowski MF, Heckman JD. Introducing levels of evidence to the journal. J Bone Joint Surg Am 2003;85-A(1):1-3

2 West S, King V, Carey TS, et al. Systems to Rate the Strength of Scientific Evidence. Evidence Report/Technology Assessment No. 47 (prepared by the Research Triangle Institute-University of North Carolina Evidence-based Practice Center, Contract No. 290-97-0011). Rockville, MD: Agency for Healthcare Research and Quality; 2002

3 Methods Guide for Effectiveness and Comparative Effectiveness Reviews. AHRQ Publication No. 10(12)-EHC063-EF. Rockville, MD. April 2012. Available at: www.effectivehealthcare.ahrq.gov

4 Atkins D, Best D, Briss PA, et al; GRADE Working Group. Grading quality of evidence and strength of recommendations. BMJ 2004;328(7454):1490

5 Kato M, Nakamura H, Konishi S, et al. Effect of preserving paraspinal muscles on postoperative axial pain in the selective cervical laminoplasty. Spine 2008;33(14):E455-E459

6 Takeuchi K, Yokoyama T, Aburakawa S, et al. Axial symptoms after cervical laminoplasty with C3 laminectomy compared with conventional C3-C7 laminoplasty: a modified laminoplasty preserving the semispinalis cervicis inserted into axis. Spine 2005;30 (22):2544-2549

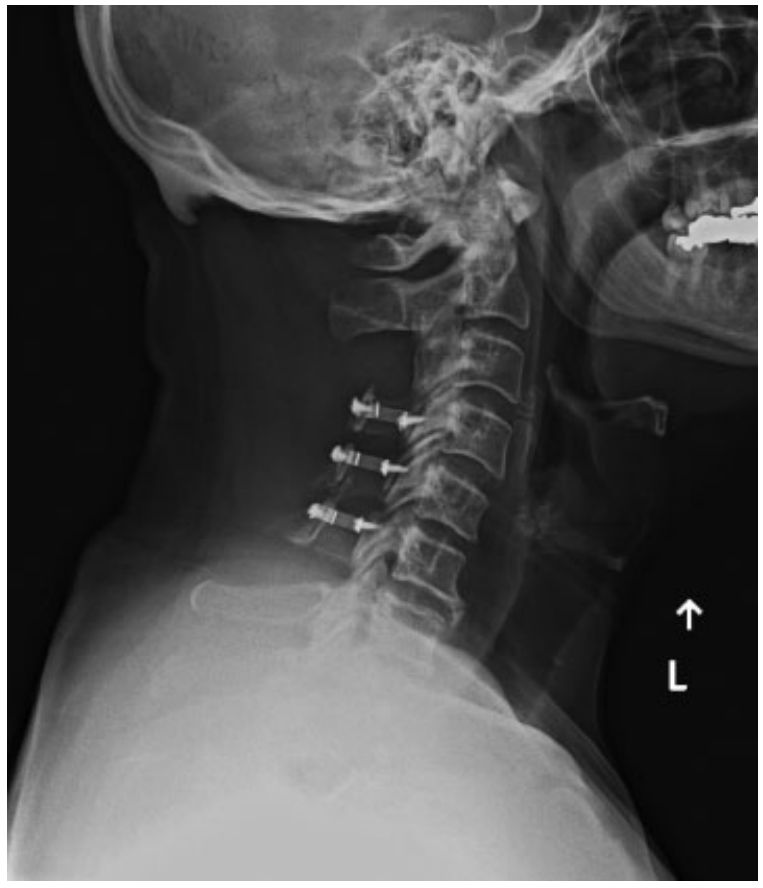

Fig. 7 Postoperative lateral.

7 Kowatari K, Ueyama K, Sannohe A, Yamasaki Y. Preserving the C7 spinous process with its muscles attached: effect on axial symptoms after cervical laminoplasty. J Orthop Sci 2009;14(3):279-284

8 Cho CB, Chough CK, Oh JY, Park HK, Lee KJ, Rha HK. Axial neck pain after cervical laminoplasty. J Korean Neurosurg Soc 2010;47(2):107-111

9 Hosono N, Sakaura H, Mukai Y, Fujii R, Yoshikawa H. C3-6 laminoplasty takes over C3-7 laminoplasty with significantly lower incidence of axial neck pain. Eur Spine J 2006;15(9):1375-1379

10 Hosono N, Sakaura H, Mukai Y, Yoshikawa H. The source of axial pain after cervical laminoplasty-C7 is more crucial than deep extensor muscles. Spine 2007;32(26):2985-2988

11 Takeuchi $\mathrm{T}$, Shono Y. Importance of preserving the $\mathrm{C} 7$ spinous process and attached nuchal ligament in French-door laminoplasty to reduce postoperative axial symptoms. Eur Spine J 2007;16(9):1417-1422

12 Sakaura H, Hosono N, Mukai Y, Fujimori T, Iwasaki M, Yoshikawa H. Preservation of muscles attached to the $\mathrm{C} 2$ and $\mathrm{C} 7$ spinous processes rather than subaxial deep extensors reduces adverse effects after cervical laminoplasty. Spine 2010;35(16):E782-E786

13 Sakaura H, Hosono N, Mukai Y, Oshima K, Iwasaki M, Yoshikawa H. Preservation of the nuchal ligament plays an important role in preventing unfavorable radiologic changes after laminoplasty. J Spinal Disord Tech 2008;21(5):338-343

14 Kotani Y, Abumi K, Ito M, et al. Minimum 2-year outcome of cervical laminoplasty with deep extensor muscle-preserving approach: impact on cervical spine function and quality of life. Eur Spine J 2009;18(5):663-671

15 Kotani Y, Abumi K, Ito M, et al. Impact of deep extensor musclepreserving approach on clinical outcome of laminoplasty for cervical spondylotic myelopathy: comparative cohort study. Eur Spine J 2012;21(8):1536-1544

16 Matz PG, Anderson PA, Groff MW, et al; Joint Section on Disorders of the Spine and Peripheral Nerves of the American Association of Neurological Surgeons and Congress of Neurological Surgeons. Cervical laminoplasty for the treatment of cervical degenerative myelopathy. J Neurosurg Spine 2009;11(2):157-169

17 Mummaneni PV, Kaiser MG, Matz PG, et al; Joint Section on Disorders of the Spine and Peripheral Nerves of the American Association of Neurological Surgeons and Congress of Neurological Surgeons. Cervical surgical techniques for the treatment of cervical spondylotic myelopathy. J Neurosurg Spine 2009;11(2):130-141 


\section{Editorial Perspective}

The authors received unanimous applause from our EBSJ reviewers for the idea of the study, the methodology, and its useful conclusions. Protracted postoperative neck pain has been one of the major concerns regarding laminoplasty surgery and this systematic review thoroughly looked at preservation of muscle attachments to the two most prominent posterior cervical spinous processes-C2 and C7. It appears that there are few downsides to this technique adaptation, aside from performing a more anatomic dissection and adjusting for a potentially more limited exposure of the transition segments by changing the decompression techniques for C3 and C7 levels. The role of postoperative immobilization is another intriguing aspect of trying to optimize patients' long-term pain outcomes following laminoplasty. Here, the current data are insufficient for a clear message. The general trend of this comparison, however, seems to point to a clear preference for limiting the duration of immobilization and maximizing opportunities for early functional recovery. This early observation seems to be an outright open invitation for a prospective trial.

In general, this systematic review endorses the general concept of laminoplasty as a successful treatment strategy for certain patients afflicted with symptomatic cervical stenosis. There seems to be room for improvement in outcomes by refining the surgical and perioperative care strategies employed. 